\title{
Lipoma in the Soft Tissues of the Floor of the Mouth: A Case Report
}

\author{
Susanna Annibali ${ }^{1}$, Maria Paola Cristalli ${ }^{1}$, Gerardo La Monaca ${ }^{1}$, Nicola Giannone $^{2}$, \\ Nunzio Francesco Testa ${ }^{3}$, Lucio Lo Russo ${ }^{2}$ and Lorenzo Lo Muzio ${ }^{*}, 2$ \\ ${ }^{I}$ Department of Dental Sciences, University La Sapienza, Rome, Italy \\ ${ }^{2}$ Department of Surgical Sciences, University of Foggia, Foggia, Italy \\ ${ }^{3}$ Department of Dentistry and Surgery, University of Bari, Bari, Italy
}

\begin{abstract}
Lipomas are common benign soft tissue neoplasms of mature adipose tissue. Most of lipomas develop in the subcutaneous tissues but deeper tissues may be involved as well; the oral cavity is not commonly affected. The overall incidence in the oral cavity is thought to be between $1 \%$ and $4.4 \%$ of all benign oral lesions. Oral lipomas can occur in various anatomic sites including the major salivary glands, buccal mucosa, lip, tongue, palate, vestibule, and floor of mouth. Although benign in nature, their progressive growth may cause interference with speech and mastication due to tumour's dimension. The present report shows the case of a 58-year old female who presented with a large intraoral lipoma.
\end{abstract}

\section{INTRODUCTION}

Lipomas are common benign soft tissue neoplasms of mature adipose tissue. The peak of incidence is usually in the fifth or sixth decade of life, while occurrence in children is very uncommon; multiple presentation may occur in about $5 \%$ of patients [1]. The tumors are either encapsulated or not. In a review of more than 1000 benign tumors of adipose tissue, over $80 \%$ were ordinary lipomas; nearly all the others were angiolipomas, intramuscular lipomas, or lipoblastomas; other types accounted for less than $2 \%$ of all benign lipomatous neoplasms [2].

Most of lipomas develop in the subcutaneous tissues but deeper tissues may be involved as well; the oral cavity is not commonly affected [3]. The overall incidence in the oral cavity is thought to be between $1 \%$ and $4.4 \%$ of all benign oral lesions [4, 5]. Oral lipomas can occur in various anatomic sites including the major salivary glands, buccal mucosa, lip, tongue, palate, vestibule, and floor of mouth [6, 7]. Some studies showed a female preponderance while others did not found gender preference [4, 8]. Although benign in nature, their continue growth may cause interference with speech and mastication due to tumour's dimension [9].

The present report shows the case of a 58 -year old female who presented with a large intraoral lipoma.

\section{CASE REPORT}

A 58-year-old otherwise healthy woman was admitted to our clinic with a painless palpable intraoral mass, which had been present for 3 years. The clinical examination revealed a mobile $20 \mathrm{~mm}$ in size mass located in the floor of the mouth (Fig. 1A). The overlying mucosa was normal in appearance with no sign of inflammation. Nothing was visible

*Address correspondence to this author at the Via Carelli 28, 71100 Foggia, Italy; Tel/Fax: (39) 881-588041; E-mails: lomuziol@tin.it, llomuzio@tin.it extra-orally. On palpation, the lesion was non-tender (Fig. 1B), but no fluid could be detected by needle aspiration (Fig. 1C). Magnetic resonance imaging revealed a mass in the floor of the mouth (Fig. 2). The histopathological analysis performed on an incisional biopsy collected sample showed lobules of mature adipose tissue consistent with a lipoma. The lesion was surgically excised under local anaesthesia. A longitudinal incision was made over the mucosa covering the tumor, blunt dissection was used throughout, and the lesion literally popped out from surrounding tissues (Fig. 1D, E). The $20 \times 12 \times 7 \mathrm{~mm}$ tumor, was yellowish in colour and well encapsulated (Fig. 1F). Mucosal layers were closed together with absorbable sutures (Monocryl ${ }^{\circledR}$ 5/0) obliterating the dead space.

Sections showed sheets of mature adipocytes and lobules of adipose tissue separated from the surface epithelium by fibrous connective tissue stroma. Tumor cells were arranged in lobules. These lobules were separated from each other by fibrovascular connective tissue septae. A histopathological diagnosis of lipoma was made.

\section{DISCUSSION}

Lipomas develop mostly in the subcutaneous tissues and only rarely in deep tissues. They most commonly involve the trunk and limbs of the body, and seldom the oral and maxillofacial region $[3,8]$. The occurrence is higher in females than in males [1]. The female to male ratio for all lipomas is 2: 1 [10], but oral lipomas occur more in men than in women (1.5:1) [10] or have no gender predilection [11]. Lipomas usually develop in patients over 40 years old; the buccal mucosa and vestibule are the most common involved intraoral sites (half of cases).

Superficial lipomas in oral and maxillofacial region sometimes can be clinically diagnosed. Palpation reveals a soft, painless, and mobile mass, which gradually enlarges over the course of several months or years. Usually, deep lipomas are not palpable. It is difficult to distinguish between 


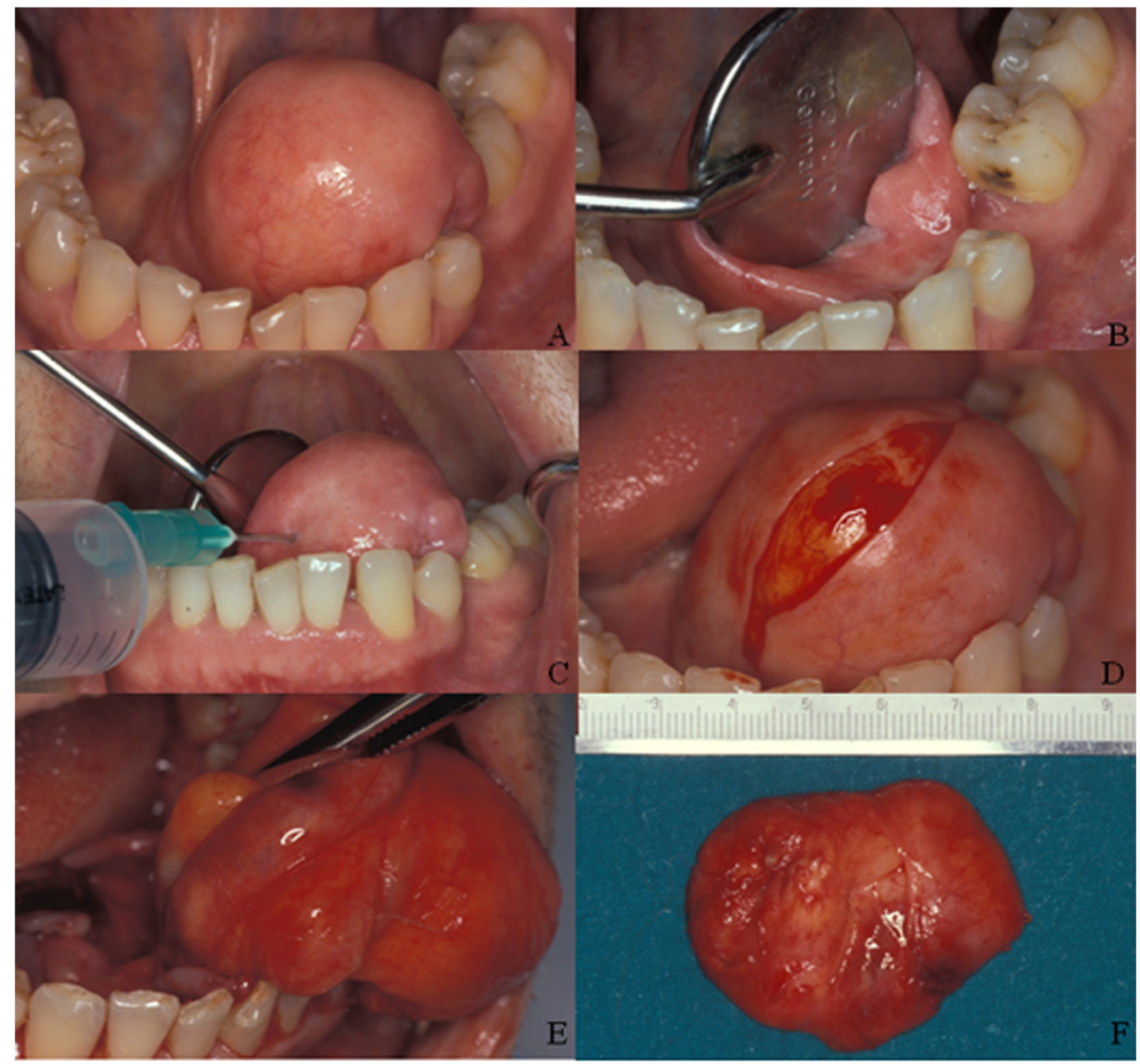

Fig. (1). (A) clinical aspect of intraoral lipoma, (B) low consistence of the mass, (C) no liquid with needle aspiration biopsy, (D) incision during surgery phases, (E) enucleation of the mass, (F) macroscopic aspect of the mass.

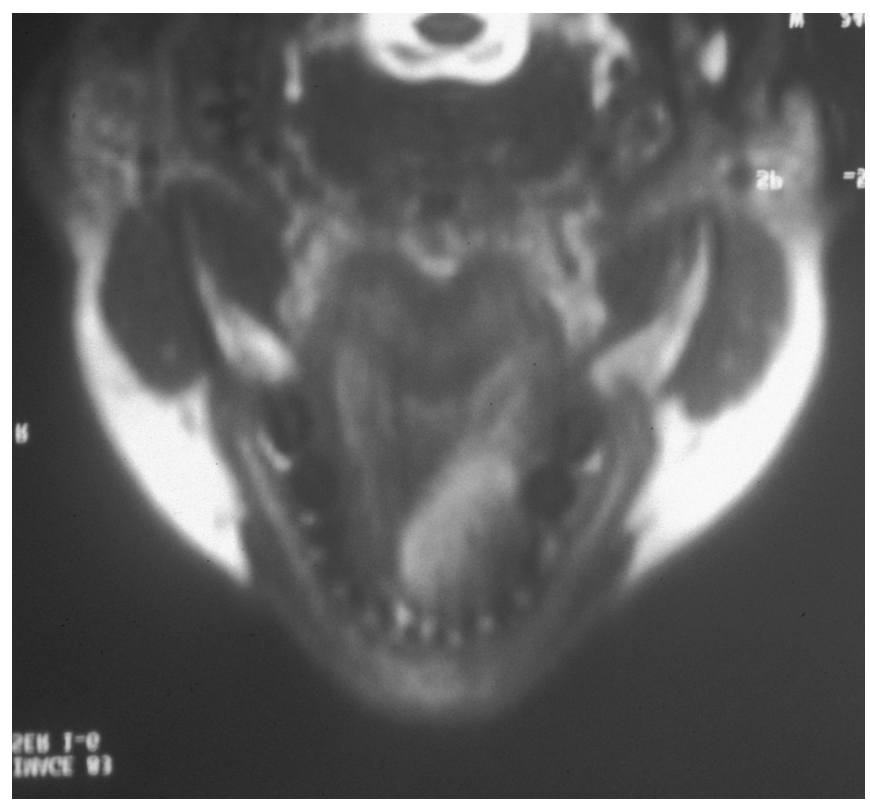

Fig. (2). Aspect of intraoral lipoma at the MRI.

the mass and the adjacent tissues, especially when the mass is adherent to muscles and salivary glands. Hence, the imaging examination may be necessary. Fine needle aspiration biopsy (FNAB) sometimes is useful for a direct diagnosis $[12,13]$. There are many imaging techniques that could be used to identify soft tissue masses, such as computerized tomography (CT), magnetic resonance imaging (MRI) and ultrasonography. Ultrasonography is quick, easy, less costly, and, with the use of high-frequency transducers, it is really suitable for evaluation of superficial structures, especially when difficulties exist in identifying the mass from adjacent tissues, as it happens in the oral and maxillofacial region. Ultrasonography shows a round or elliptical in shape lesion, with intact or mostly intact capsule. Most of lipomas are hypo-echoic with echogenic lines or spots $[14,15]$. However, the soft tissue characterization with ultrasonography is less specific than CT or MRI. When the mass is difficult to identify on ultrasonogram, CT or MRI is necessary $[1,16,17]$. Lipoma has a characteristic radiographic appearance. On CT scan it shows a high density from 83 to 143 Haunsfield units with well or poorly defined margins depending on the capsule.

Despite the close histological similarity to normal adipose tissue, lipomas, usually, have chromosomal aberrations such as translocations involving 12q13-15, locus interstitial deletions of $13 \mathrm{q}$, and rearrangements involving 
8q11-13 locus [18]. The clinical differential diagnosis includes ranula, dermoid cyst, thyroglossal duct cyst, ectopic thyroid tissue, pleomorphic adenoma and mucoepidermoid carcinoma, angiolipoma, fibrolipoma and malignant lymphoma $[15,19,20]$. The definitive diagnosis is made by means of microscopic examination which shows adult fat tissue cells embedded in a stroma of connective tissue and surrounded by a fibrous capsule [20]. A histopathologic differential diagnosis appropriate to the oral cavity would include fibrosarcoma if spindle cells are not localized and numerous [21]. Other lesions should be also considered: they include schwannoma, myxoid neurofibroma, leiomyoma, nodular fasciitis, myxolipoma, fibrolipoma, malignant fibrous histiocytoma, myxoid liposarcoma, and myxoid solitary fibrous tumour.

The prognosis of this tumor is always good. In adults, the recurrence is rare after complete surgical resection; nonetheless, Cao et al. reported recurrence in patients under 18 years old, and development of liposarcoma after several recurrences. Long-term follow-up is necessary in patients under 18 years old [14]. Surgical resection is the main treatment for lipoma. The complete resection should be emphasized during the first surgical operation, which is the key factor in order to avoid recurrence [15, 22]. Wellencapsulated lipomas, as the present case, easily shell out with no possibility of recurrence or damage to the surrounding structures.

\section{REFERENCES}

[1] Fornage BD, Tassin GB. Sonographic appearances of superficial soft tissue lipomas. J Clin Ultrasound 1991; 19: 215-20.

[2] Saitoh Y, Hama T, Ishizaka S, et al. Fibrolipoma of the parotid in a child. Am J Otolaryngol 1995; 16: 433-5.

[3] Dattilo DJ, Ige JT, Nwana EJ. Intraoral lipoma of the tongue and submandibular space: report of a case. J Oral Maxillofac Surg 1996; 54: 915-7.

[4] Fregnani ER, Pires FR, Falzoni R, Lopes MA, Vargas PA. Lipomas of the oral cavity: clinical findings, histological classification and proliferative activity of 46 cases. Int J Oral Maxillofac Surg 2003; 32: 49-53.

[5] Lombardi T, Odell EW. Spindle cell lipoma of the oral cavity: report of a case. J Oral Pathol Med 1994; 23: 237-9.
[6] Jablokow VR, Bavafa S. Lipomas of the tongue--report of two cases. J Surg Oncol 1982; 21: 114-6.

[7] Fasig JH, Robinson RA, McCulloch TM, Fletcher MS, Miller CK. Spindle cell lipoma of the parotid: fine-needle aspiration and histologic findings. Arch Pathol Lab Med 2001; 125: 820-1.

[8] Epivatianos A, Markopoulos AK, Papanayotou P. Benign tumors of adipose tissue of the oral cavity: a clinicopathologic study of 13 cases. J Oral Maxillofac Surg 2000; 58: 1113-7; discussion 8.

[9] Chidzonga MM, Mahomva L, Marimo C. Gigantic tongue lipoma: a case report. Med Oral Patol Oral Cir Bucal 2006; 11: E437-9.

[10] de Visscher JG. Lipomas and fibrolipomas of the oral cavity. J Maxillofac Surg 1982; 10: 177-81.

[11] MacGregor AJ, Dyson DP. Oral lipoma. A review of the literature and report of twelve new cases. Oral Surg Oral Med Oral Pathol 1966; 21: 770-7.

[12] Ahuja AT, King AD, Kew J, King W, Metreweli C. Head and neck lipomas: sonographic appearance. AJNR Am J Neuroradiol 1998; 19: 505-8.

[13] Layfield LJ, Glasgow BJ, Goldstein N, Lufkin R. Lipomatous lesions of the parotid gland. Potential pitfalls in fine needle aspiration biopsy diagnosis. Acta Cytol 1991; 35: 553-6.

[14] Zhong LP, Zhao SF, Chen GF, Ping FY. Ultrasonographic appearance of lipoma in the oral and maxillofacial region. Oral Surg Oral Med Oral Pathol Oral Radiol Endod 2004; 98: 738-40.

[15] Del Castillo Pardo de Vera JL, Cebrian Carretero JL, Gomez Garcia E. Chronic lingual ulceration caused by lipoma of the oral cavity. Case report. Med Oral 2004; 9: 166-7, 3-6.

[16] Gritzmann N, Hollerweger A, Macheiner P, Rettenbacher $T$. Sonography of soft tissue masses of the neck. J Clin Ultrasound 2002; 30: 356-73.

[17] Gritzmann N, Schratter M, Traxler M, Helmer M. Sonography and computed tomography in deep cervical lipomas and lipomatosis of the neck. J Ultrasound Med 1988; 7: 451-6.

[18] Enzinger FW, Weiss SW. Soft tissue tumors. 4 ed. St. Louis: Mosby 2001

[19] Capodiferro S, Scully C, Maiorano E, Lo Muzio L, Favia G. Liposarcoma circumscriptum (lipoma-like) of the tongue: report of a case. Oral Dis 2004; 10: 398-400.

[20] Piattelli A, Rubini C, Fioroni M, Iezzi G. Spindle-cell lipoma of the cheek: a case report. Oral Oncol 2000; 36: 495-6.

[21] Tosios K, Papanicolaou SI, Kapranos N, Papadogeorgakis N. Spindle cell lipoma of the oral cavity. Int J Oral Maxillofac Surg 1995; $24: 363-4$

[22] Furlong MA, Fanburg-Smith JC, Childers EL. Lipoma of the oral and maxillofacial region: Site and subclassification of 125 cases. Oral Surg Oral Med Oral Pathol Oral Radiol Endod 2004; 98: 44150 